\title{
The Rank of Silaturrahmi-Assimilated Collaboration Parameter Based on Core Drive Using Octalysis Gamification Framework and Fuzzy AHP
}

\author{
Fitri Marisa ${ }^{1,2}$, Sharifah Sakinah Syed Ahmad ${ }^{2}$, Zeratul Izzah Mohd Yusoh ${ }^{2}$, \\ Titien Agustina ${ }^{3}$, Anastasia L Maukar ${ }^{4}$, Endah Tri Esti Handayani ${ }^{5}$, Slamet Risnanto ${ }^{6}$ \\ ${ }^{1}$ Department of Informatics Engineering, Widyagama University of Malang, Malang, Indonesia \\ ${ }^{2}$ Faculty of Information and Communication Technology, Universiti Teknikal Malaysia Melaka, Malaysia \\ ${ }^{3}$ Department of Management, STIMI Banjarmasin, Banjarmasin, Indonesia \\ ${ }^{4}$ Faculty of Industrial Engineering, President University, Bekasi, Indonesia \\ ${ }^{5}$ Faculty of Information Technology and Informatics, Universitas Nasional, Jakarta, Indonesia \\ ${ }^{6}$ Faculty of Engineering, Universitas Sangga Buana, Bandung, Indonesia
}

\begin{abstract}
This study aims to build SME collaboration parameters from the assimilation of the "silaturrahmi" culture that considers user motivation in collaborating. Parameter validation involves linear regression statistical methods, followed by determining the ranking of collaboration parameters using a combination model of Octalysis and Fuzzy AHP frameworks. The test resulted in 4 collaboration parameters from the assimilation of "Silaturrahmi" ranked based on the user's level of motivation (core drive) with details: Relationship Building-RB (52.86\%), Reciprocal Sustainment-RS (25.44\%), Reciprocal Assistant-RA (21.77\%) and Active SupportUS $(0.83 \%)$. It can be concluded that the four parameters potentially measure the performance of SME collaboration. The combination model can determine the user's motivation (core drive) for collaboration through these parameters.
\end{abstract}

DOI: 10.18421/TEM104-63

https://doi.org/10.18421/TEM104-63

Corresponding author: Fitri Marisa,

${ }^{1}$ Widyagama University of Malang, Malang, Indonesia

${ }^{2}$ Universiti Teknikal Malaysia Melaka, Malaysia

Email: fitrimarisa@gmail.com

Received: 07 August 2021.

Revised: 14 November 2021.

Accepted: 20 November 2021.

Published: 26 November 2021.

(c) BY-NC-ND (C) 2021 Fitri Marisa et al; published by UIKTEN. This work is licensed under the Creative Commons Attribution-NonCommercial-NoDerivs 4.0 License.

The article is published with Open Access at www.temjournal.com
The ranking results serve as a reference for developing a collaborative framework by prioritizing activities related to the highest weight percentage parameters and evaluating the lowest weight percentage.

Keywords - Collaboration Parameter, Silaturrahmi culture, Core Drive, Octalysis Gamification, Fuzzy AHP

\section{Introduction}

Small and Medium Enterprise (SME) is an important component of the country's economy, especially in developing countries including Indonesia[1],[2]. However, there are still many challenges to be solved such as recommendation system needs, also especially in facing the global market [1],[3],[4]. While in the process of improving themselves to face the global market, the SME is faced with the Covid-19 pandemic situation which of course makes it more difficult to move causing a significant decline in growth and development [5]. One solution in the context of recovering conditions and business sustainability is to strengthen collaboration between SMEs [5] where collaboration allows SMEs to carry out positive activities such as exchanging information and business cooperation in order to strengthen each other [6], [7]. However, the current implementation of SME collaboration still tends to be weak due to the lack of motivation to collaborate and lack of awareness of collaboration [5]. The lack of emotional closeness between SME actors is also the cause of weak collaboration [5]. In addition, there is also no appropriate collaboration framework that can motivate and raise awareness of the importance of collaborating [8], [9], [10], [11], [12]. 
Therefore, this research focuses on building collaboration parameters which are an important part of the collaboration framework that serves as a guide for determining collaboration activities and measuring collaboration performance. Meanwhile, SMEs cannot be separated from the influence of local wisdom as one of the roots of thought and behavior. Local wisdom that applies in the community is proven to affect the mindset of each individual [6], [1], [7]. Among the prevailing local wisdom, there is "Silaturrahmi" which has the principle of establishing closeness with other people [13], [14], [15]. "Silaturrahmi" has 4 principles, including Relationship Building, Reciprocal Sustainment, Reciprocal Assistant and Active Support where each principle aims to establish closeness [13], [14], [15]. Therefore, "Silaturahmi" needs to be assimilated in building collaboration parameters by considering efforts to increase closeness between partners. This assimilation is also expected to be adaptive in the community so that it can improve collaboration performance.

In improving collaboration performance, a strategy is needed to increase collaboration motivation. For this reason, the parameters that are built also need to involve an approach that can measure the user's motivation for each parameter in detail. Referring to the point of view of the Octalysis gamification framework, a behavior occurs because there are 8 types of motivation (core drives) involved (Figure 1., Figure 2.) [16], [17], [18], [19], [20]. Therefore, these 8 core drives need to be considered in building collaboration parameters so that they can measure collaboration motivation in more detail.

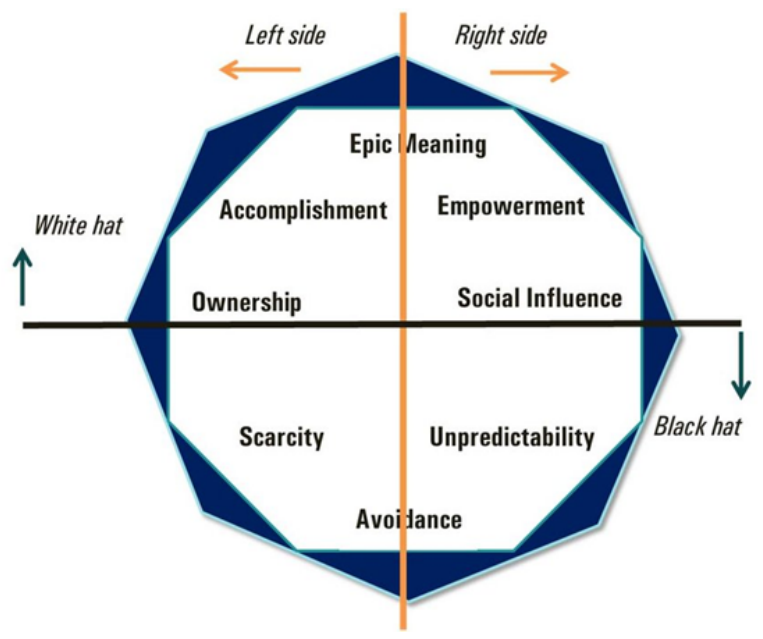

Figure 1. Octalysis Gamification Framework [20]
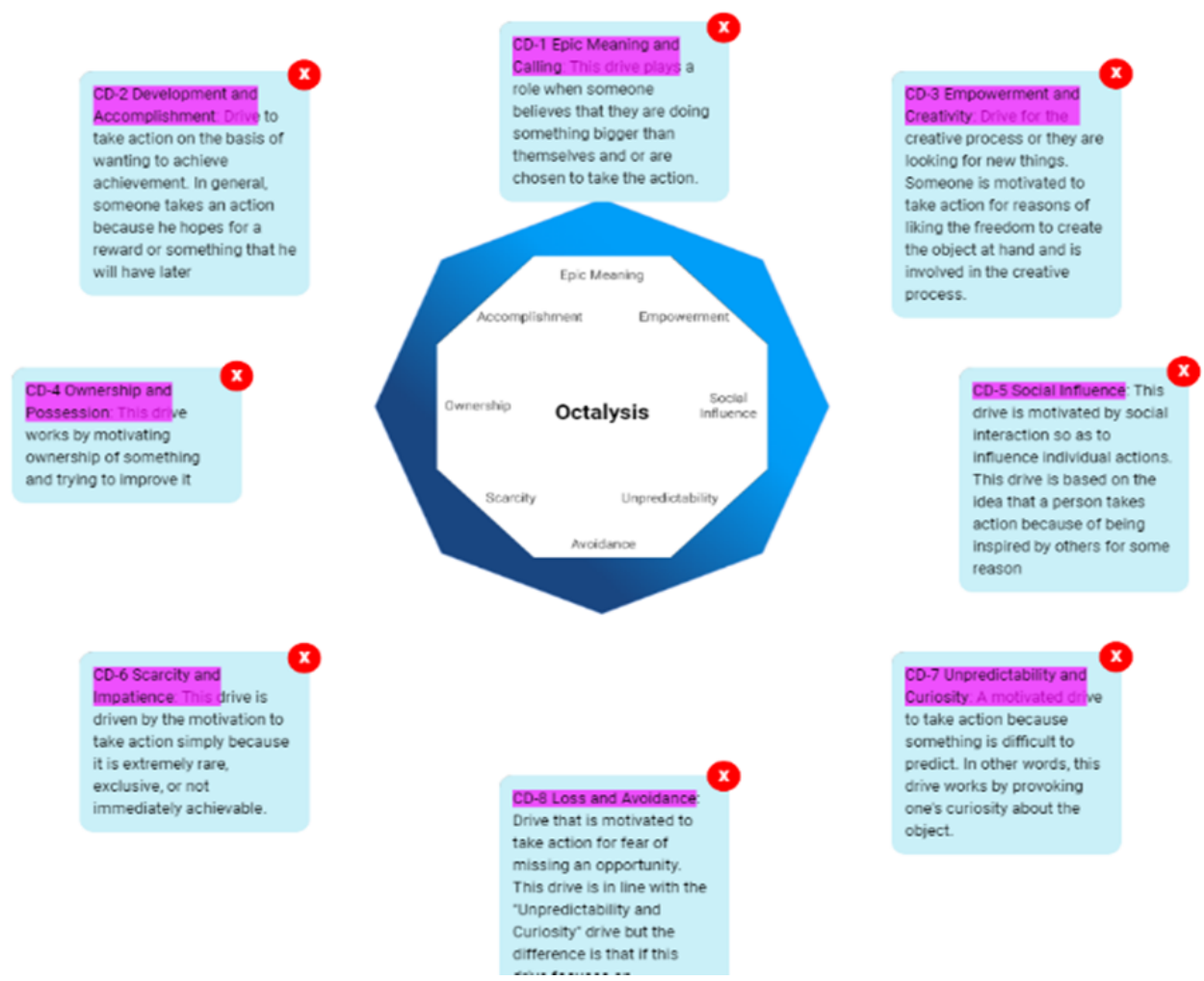

Figure 2. Detail of Octalysis [20],[18]

In measuring the motivation to collaborate, each parameter also needs to be ranked at the level of its contributor to motivation. This needs to be done to create a priority guideline for collaborative activities that can refer to these parameters for more targeted activities. Therefore, the collaboration parameters are ranked using the Fuzzy Analytic Hierarchy Process (Fuzzy AHP) and the Octalysis scale.

The AHP is a theory of measurement that is used to find the ratio scale by performing pairwise 
comparisons between factors. In determining the weight of the criteria and priorities, the alternatives are structured in a way based on pairwise comparisons. However, this is vulnerable if subjective judgments occur during comparisons so that they can result in inaccurate decisions [21], [22], [23]. Meanwhile, Fuzzy Logic is a logic that has a value of fuzziness between two values. The value is uncertain or inaccurate, usually the assessment is carried out using linguistic values such as "high", "low", "good", "medium", and others [21], [22], [23]. Therefore, by considering the subjective factors, as well as taking into account the validity of the data with the inconsistency tolerance limit of the selected criteria, the AHP is combined with an approach with fuzzy logic to become Fuzzy AHP [21], [22], [23]. Thus, Fuzzy AHP has advantages in ranking by getting more accurate weighting values [24], [25], [21].
Therefore, this research involves a statistical linear regression approach, Octalysis Framework and Fuzzy AHP to produce collaboration parameters based on "silaturrahmi" which are ranked based on the level of motivation (core drive) as a guide for determining collaboration activities and measuring their performance.

\section{Research Method}

The research method (Figure 3.) is divided into five (5) activities, starting with hypothesis testing proving the principle of friendship as a parameter of collaboration. Then data is collected through questionnaires for parameter weighting test, followed by parameter weighting activity with fuzzy AHP and perform weighting and core drive analysis with octalysis in parallel. Then, the two weighting results are compared as a result of the validated collaboration parameter ranking.

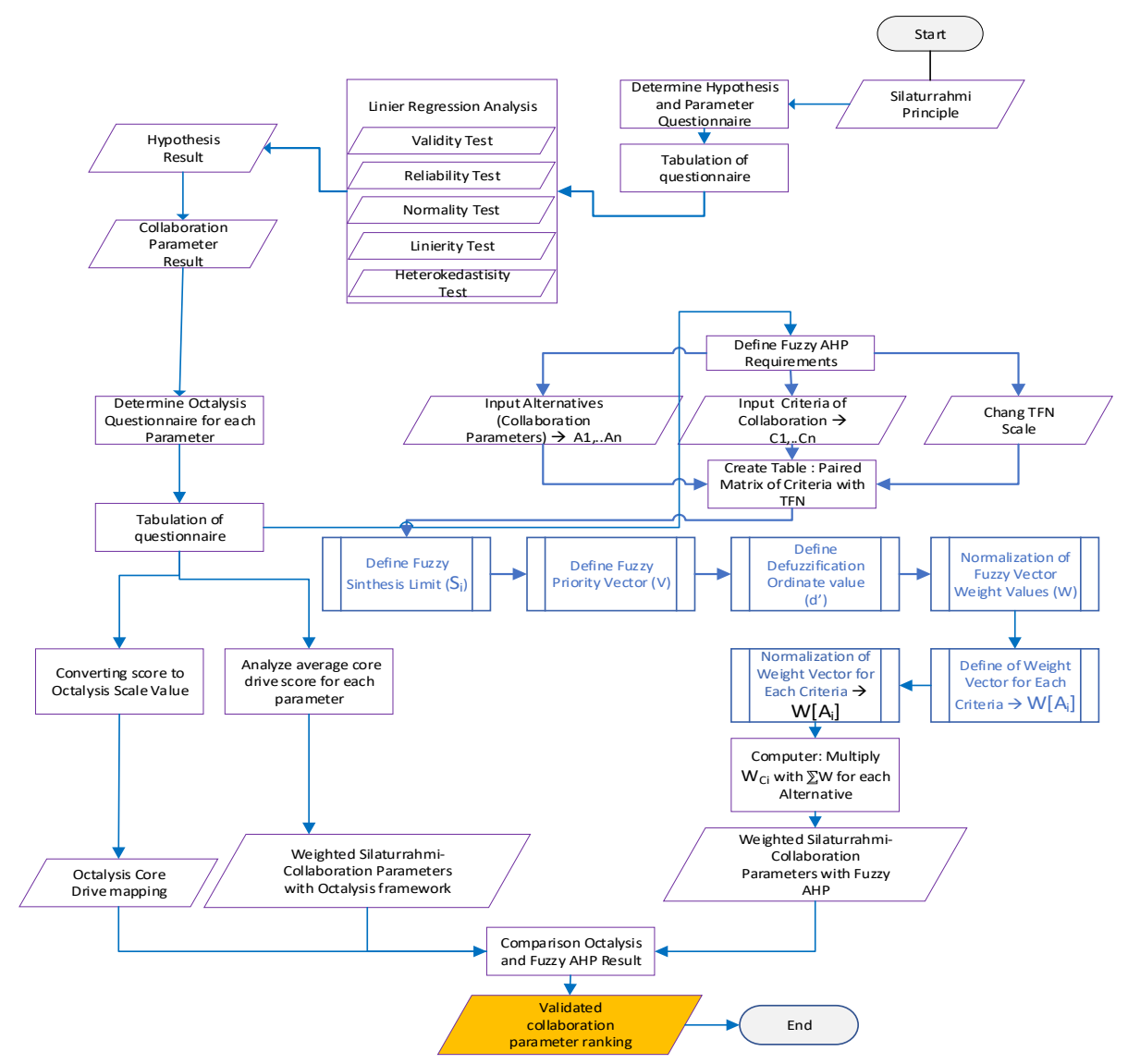

Figure 3. Research method

\subsection{Hypothesis test of Collaboration Parameter}

This stage is the process of testing the principle of "silaturrami" as a parameter of collaboration. The first step is to identify candidate collaboration parameters. [26], [27], [28] and the principle of silaturrahmi [29], [30], [13], [31], [14] then the two slices are taken connecting the two based on the literature. Then a hypothesis is built which states the influence of the "silaturrahmi" principle on collaboration. The hypothesis is proven by linear regression analysis, which previously tested the validity of the data. The analysis involved 5 tests of linear regression requirements including validity, reliability, normality, linearity and heteroscedasticity tests [32], [33]. 


\subsection{Collecting the Data}

Data collection is done by designing and distributing questionnaires by selecting respondents according to the relevance of data needs. The questionnaire is designed to collect data on the condition of 8 core drives from each parameter. In connection with the need for data analysis using octalysis, the answer

\section{Table 1. Likert Scale}

format uses an ordinal type with a Likert scale of 5 answers (Table 1.).

\begin{tabular}{cc}
\hline Value & Declaration \\
\hline 1 & Very Weak \\
2 & Weak \\
3 & Neutral \\
4 & Strong \\
5 & Very Strong \\
\hline
\end{tabular}

\subsection{Octalysis Scale Analysis}

Octalysis scale analysis was carried out to obtain the motivational potential pattern of each parameter, so that the role of each parameter in contributing to the increase in SME motivation in collaborating. This mapping refers to the octalysis approach [34]. The steps include:

1. Analyze the questionnaire data in each core drive by making a scale/level of grouping size.

2. Calculate the total score obtained by each core drive and the total results are categorized with the reference level that has been set and then tabulated.

3. Analyze the questionnaire data with octalysis scale, then convert the values from Likert scale to octalysis scale on each core drive and then tabulate the results and multiply the results by 2 to get the octalysis value of each parameter.

4. Calculate the average value of each core drive for each parameter, to find out the weight of each parameter.

\subsection{Fuzzy AHP analysis}

Fuzzy AHP analysis aims to weight the parameters of the 4 parameters. This test aims to determine the potential motivation of each player to the 4 collaboration parameters based on the criteria of 8 core drives Octalysis. Weighting methods that are commonly used include the Analytical Hierarchy Process (AHP), where criteria and alternatives must be prepared in the processing, but AHP has not been able to solve vague problems, for that a Fuzzy-AHP method is needed to solve it so that the weighting results get a more accurate value. [24], [25]. [21], [22], [23]. Here are the steps:

1. Prepare the need for Fuzzy AHP analysis, including: a) criteria taken from the collaboration criteria in the literature, b) alternatives taken from parameters generated from linear regression tests and c) preparing TFN measuring scale as a reference for weights assessed by SME practitioners designated through a questionnaire.

2. After the TFN table from the data to be analyzed is formed, then define the limit synthesis fuzzy vector ( $\mathrm{Si})$, by calculating the lower, median, upper totals of each column and calculating the total of the three, proceed to calculate the total of the synthesis values and calculate the value sum of the synthesis scores for each criterion.

3. Define the Priority Vector (V) value, by calculating the vector value for each criterion and tabulating it.

4. Define the defuzzification ordinate value (d') by calculating the minimum value of the vector value for each criterion, then tabulation is carried out.

5. Normalize the Fuzzy vector weight (W) by calculating the weight value of each criterion then tabulated.

6. Define the vector weight of each criterion W[Ai] by calculating the min and max values for each criterion, calculating the vector weight of each criterion and tabulating it.

7. Normalize the vector weights of each criterion and tabulate it.

8. Rank collaboration parameters by multiplying the weight vector value of each criterion with the weight vector value for each criterion that represents the weight, so that the weighted collaboration parameter is produced.

\subsection{Comparison Weighting Result}

This phase is comparing the two weighting results of Octalysis and Fuzzy AHP. This activity aims to observe the consistency of the weight results between the two as a measure to determine the ranking of validated parameters that will be used as material for collaborative gamification scenarios.

\section{Result and Discussion}

This section describes the test results with reference to the research methods that have been defined.

\subsection{Parameter Determining Result}

The test starts from defining candidate parameters resulting from the intersection between the collaboration principle and the principle of "silaturrahmi" (Table 2.). 
Table 2. Intersection of parameter candidate based on literature review

\begin{tabular}{|c|c|c|}
\hline $\begin{array}{c}\text { Collaboration } \\
\text { Principles } \\
\end{array}$ & $\begin{array}{c}\text { Silaturrahmi" } \\
\text { Principles }\end{array}$ & Literature \\
\hline \multirow{2}{*}{$\begin{array}{l}\text { The Closenest } \\
\text { of Relationship }\end{array}$} & Relationship & {$[26],[30],[13]$,} \\
\hline & Building (RB) & {$[31],[29],[14]$} \\
\hline Positive & Reciprocal & [28][30] [1] \\
\hline Dependency & $\begin{array}{l}\text { Sustainment } \\
\text { (RS) }\end{array}$ & {$[31],[29],[14]$} \\
\hline \multirow{2}{*}{ Social Activity } & Reciprocal & {$[28],[30],[13]$,} \\
\hline & Assistant (RA) & {$[31],[29],[14]$} \\
\hline
\end{tabular}

\begin{tabular}{clc}
\hline $\begin{array}{c}\text { Collaboration } \\
\text { Principles }\end{array}$ & $\begin{array}{c}\text { "Silaturrahmi" } \\
\text { Principles }\end{array}$ & Literature \\
\hline & Active Support & {$[28],[30],[13]$,} \\
Group Activity & (AS) & {$[31],[29][29]$,} \\
& & {$[14]$} \\
\hline
\end{tabular}

Then the hypothesis testing is carried out with linear regression analysis accompanied by the requirements test, where the test results have been described in Table 3.

Table 3 and 4. Hypothesis test result

\begin{tabular}{|c|c|c|c|c|c|c|c|c|}
\hline \multirow[t]{2}{*}{ Variables } & \multicolumn{5}{|c|}{ Requirement Tests } & \multicolumn{2}{|c|}{$\begin{array}{l}\text { Linier } \\
\text { Regression }\end{array}$} & \multirow[t]{2}{*}{ Hyphotesis } \\
\hline & Validity & Reliability & Normality & Linierity & $\begin{array}{l}\text { Hetero } \\
\text { kedastisity }\end{array}$ & Sig. & $\begin{array}{l}\mathrm{T} \\
\text { value }\end{array}$ & \\
\hline X1-RB & 0.000 & 0.757 & 0.200 & 0.166 & 0.500 & 0.005 & 2.882 & Accepted \\
\hline X2-RS & 0.000 & 0.729 & 0.200 & 0.224 & 0.552 & 0.000 & 4.050 & Accepted \\
\hline X3-RA & 0.000 & 0.786 & 0.200 & 0.74 & 0.773 & 0.000 & 4.746 & Accepted \\
\hline X4-AS & 0.000 & 0.760 & 0.200 & 0.148 & 0.165 & 0.000 & 6.230 & Accepted \\
\hline $\begin{array}{l}\text { Y- } \\
\text { Collaboration }\end{array}$ & 0.000 & 0.737 & 0.200 & & & & & \\
\hline
\end{tabular}

From testing the candidate parameters, the results of the linear regression requirements test and the results of linear regression analysis have been obtained. Test requirements include validity with the condition that the significance value is $<0.05$, and the validity value that has been obtained is proven to meet the requirements. Reliability test with reference to the Cronbach alpha value $>0.06$, and the reliability value that has been obtained is proven to meet the requirements. Normality test with a reference value of significance $>0.05$, and the normality value that has been obtained is proven to meet the requirements. Linearity test with a reference value of significance $>0.05$, and the significance value that has been obtained is proven to meet the requirements. Heteroscedasticity test with reference to the significance value $>0.05$, and the heteroscedasticity value that has been obtained is proven to meet the requirements. Then all the test requirements on the collaboration parameter test data have met the requirements, then proceed to linear regression analysis.

Furthermore, based on linear regression analysis, the effect of each variable X1 (Relationship Building$\mathrm{RB}), \mathrm{X} 2$
(Reciprocal Sustainment-RS), X3 (Reciprocal Assistant-RA) and X4 (Active Support-AS) on variable $Y$ (Collaboration) is to get the results of the significance value $<0.05$ and t-value $>t$-table, which means that each variable has a significant positive effect on collaboration. Thus, the hypothesis is accepted and the 4 candidate parameters have been validated to become collaboration parameters.

\subsection{The Data Tabulation Result}

The data collection was carried out by distributing questionnaires, where the respondents selected were actors and at the same time activators of SME networks in their environment that had at least 5 years of business that were still productive. The number of respondents who filled in 30 respondents and after removing the outliers to 29 were used in this test. The questionnaire was designed by defining 8 questions according to the number of core drives for 4 collaboration parameters, so that the total questionnaire questions were 32. Meanwhile, the answer format uses a 5-answer Likert scale with consideration to match the conversion process into a Likert scale. Tabulated data is presented in Table 5. 
Table 5. The data tabulation result

\begin{tabular}{lcccccccc}
\hline \multicolumn{1}{c}{ Alternative } & \multicolumn{9}{c}{ Criteria } \\
& C1 & C2 & C3 & C4 & C5 & C6 & C7 & C8 \\
\hline A1 - Relationship Building & 126 & 128 & 129 & 123 & 120 & 100 & 120 & 123 \\
A2 Reciprocal & 122 & 113 & 122 & 114 & 122 & 102 & 118 & 118 \\
Sustainment & 120 & 110 & 121 & 111 & 125 & 106 & 116 & 114 \\
A3 - Reciprocal Assistant & 119 & 115 & 123 & 122 & 124 & 109 & 109 & 107 \\
A4 - Active Support & 487 & 466 & 495 & 470 & 491 & 417 & 463 & 462 \\
\hline \multicolumn{1}{c}{ Total } & & & &
\end{tabular}

\subsection{Octalysis Scale Analysis Result}

The first test is to get the Octalysis conversion value. This test is needed to obtain the details of the core drive mapping of each collaboration parameter. The questionnaire data were grouped and tabulated based on the core drive so that 8 data groups were formed. The score of the questionnaire is in the range of 1 to 5 , while

Table 6. Octalysis Tabulation Score Each Core Drive the octalysis score is in the range of 1 to 10 . To get the octalysis score, the questionnaire data is calculated on average for each core drive and then multiplied by 2 in order to get a conversion result that is equivalent to the value octalysis benchmark score. After getting the octalysis score, a comparison tabulation of the octalysis value of the 4 parameters and the target is made which is the standard for the highest octalysis value (Table 6.).

\begin{tabular}{llllll}
\hline Core Drive & Target & $\begin{array}{l}\text { Actual } \\
\text { RB }\end{array}$ & & & \\
& & & RA \\
& & & AS \\
& & 10 & 8 & 8 & 8 \\
\hline 1.Epic Meaning and Calling & 10 & 10 & 8 & 8 & 8 \\
2.Development & 10 & & & & \\
Accomplishment & & & 8 & 8 & 8 \\
3.Empowering of Creativity & 10 & 8 & 8 & 8 & 8 \\
4.Social Influence and Relatedness & 10 & 8 & 8 & 8 & 8 \\
5.Ownership and Possession & 10 & 8 & 8 & 8 & 8 \\
6.Scarcity and Impatience & 10 & 8 & 8 & 8 & 8 \\
7.Unpredictability and Curiosity & 10 & 8 & 8 & 8 & 8 \\
8.Loss and Avoidance & 10 & & & & \\
\hline
\end{tabular}

The second test is to get a comparison score of the average weight of each collaboration parameter based on octalysis so that it can produce a ranking of parameters based on the level of motivation (Table 7.).

Table 7. Weight of each parameter based on octalysis

\begin{tabular}{llllllllll}
\hline Parameter & C1 & C2 & C2 & C4 & C5 & C6 & C7 & C8 & AVG \\
\hline RB & 126 & 128 & 129 & 123 & 120 & 100 & 120 & 123 & 121 \\
RS & 122 & 113 & 122 & 114 & 122 & 102 & 118 & 118 & 116 \\
RA & 120 & 110 & 121 & 111 & 125 & 106 & 116 & 114 & 116 \\
AS & 119 & 115 & 123 & 122 & 124 & 109 & 109 & 107 & 116 \\
\hline
\end{tabular}

From the test results of the two models Table 6. and Table 7. Were obtained comparable results, where Parameter Relationship Building (RB) produces the highest weight score and the value of core drive Octalysis is greater than the four parameters that have been tested (Table 6.). The RB has 3 maximum core drive scores on target (10) and the rest gets a score of 8 . While "Reciprocal Sustainment", "Reciprocal Assistant" and "Active Support" get a score of 8 for all core drives.
Meanwhile, if viewed from the weighting results in Table 7., Relationship Building also produces the highest average core drive parameter weight among the others at 121, while the other three parameters get an average value of 116 each. From the results of this test, it can be said that the results of the analysis have shown consistent data. 


\subsection{Fuzzy AHP Analysis Result}

Fuzzy AHP analysis in this test is divided into several steps to produce the weight of the collaboration parameters. The weighted data are four collaboration parameters: Relationship Building (RB), Reciprocal Sustainment (RS), Reciprocal Assistant (RA) and Active Support (AS) which are referred to as alternatives. Meanwhile, the criteria are data 8 core drives octalysis.

\subsubsection{Define the TFN (Triangular Fuzzy Number) scale}

Triangular Fuzzy Number (TFN) is used in the fuzzification process which consists of three membership functions, the lowest value (1), the middle value $(\mathrm{m})$, and the highest value $(\mathrm{u})$ [23] [22]. Determination of the TFN is guided by Linguistic Variable and Triangular Fuzzy Number (Table 11.).

Table 8. TFN scale

\begin{tabular}{llcc}
\hline Intensity & \multicolumn{1}{c}{ Linguistic Variable } & $\begin{array}{c}\text { Triangle Fuzzy } \\
\text { Number (TFN) }\end{array}$ & $\begin{array}{c}\text { Reciprocal TFN } \\
\text { Number } \\
(1,1,1)\end{array}$ \\
1 & Equal significant & $(1,1,1)$ & $(2 / 3,1,2)$ \\
2 & Equally to average significant & $(1 / 2,1,3 / 2)$ & $(1 / 2,2 / 3,1)$ \\
3 & Averagely significant & $(1,3 / 2,2)$ & $(2 / 5,1 / 2,2 / 3)$ \\
4 & Averagely to strongly significant & $(3 / 2,2,5 / 2)$ & $(1 / 3,2 / 5,1 / 2)$ \\
5 & Strongly significant & $(2,5 / 2,3)$ & $(2 / 7,1 / 3,2 / 5)$ \\
6 & Strongly to very strongly significant & $(5 / 2,3,7 / 2)$ & $(1 / 4,2 / 7,1 / 3)$ \\
7 & Very strongly significant & $(3,7 / 2,4)$ & $(2 / 9,1 / 4,2 / 7)$ \\
8 & Very strongly to extremely significant & $(7 / 2,4,9 / 2)$ & $(2 / 9,2 / 9,1 / 4)$ \\
9 & Extremenly significant & $(4,9 / 2,9 / 2)$ & \\
\hline
\end{tabular}

\subsubsection{Determining the Comparison of Paired Matrices}

This stage is to determine the priority comparison between the criteria with the TFN scale which refers to Table 8 . and determine the comparison of the paired matrix between the criteria with the TFN scale so that the values of $1, \mathrm{~m}$ and $\mathrm{u}$ are obtained for each criterion in the paired matrix (Table 12.). The determination of the TFN scale value is based on the comparison of the total value obtained for each core drive in Table 5 .

Table 9. The comparison of paired matrices between criteria with the TFN scale

\begin{tabular}{|c|c|c|c|c|c|c|c|c|c|c|c|c|c|c|c|c|c|c|c|c|c|c|c|c|}
\hline & \multicolumn{3}{|c|}{ C1 } & \multicolumn{3}{|c|}{ C2 } & \multicolumn{3}{|c|}{ C3 } & \multicolumn{3}{|c|}{ C4 } & \multicolumn{3}{|c|}{ C5 } & \multicolumn{3}{|c|}{ C6 } & \multicolumn{3}{|c|}{ C7 } & \multicolumn{3}{|c|}{ C8 } \\
\hline & $\mathrm{L}$ & $\mathrm{M}$ & U & $\mathrm{L}$ & $M$ & U & $\mathrm{L}$ & $M$ & U & $\mathrm{L}$ & $M$ & U & $\mathrm{L}$ & $M$ & U & $\mathrm{L}$ & $\mathrm{M}$ & $U$ & $\mathrm{~L}$ & $M$ & U & $\mathrm{L}$ & $M$ & U \\
\hline C1 & 1.00 & 1.00 & 1.00 & 1.00 & 1.50 & 2.00 & 0.50 & 0.67 & 1.00 & 0.50 & 1.00 & 1.50 & 0.67 & 1.00 & 2.00 & 4.00 & 4.50 & 4.50 & 1.00 & 1.50 & 2.00 & 1.00 & 1.50 & 2.00 \\
\hline C2 & 0.50 & 0.67 & 1.00 & 1.00 & 1.00 & 1.00 & 0.33 & 0.40 & 0.50 & 0.67 & 1.00 & 2.00 & 0.40 & 0.50 & 0.67 & 0.25 & 0.29 & 0.33 & 0.50 & 1.00 & 1.50 & 0.50 & 1.00 & 1.50 \\
\hline C3 & 1.00 & 1.50 & 2.00 & 2.00 & 2.50 & 3.00 & 1.00 & 1.00 & 1.00 & 1.00 & 1.50 & 2.00 & 0.50 & 1.00 & 1.50 & 4.00 & 4.50 & 4.50 & 2.00 & 2.50 & 3.00 & 5.00 & 2.50 & 3.00 \\
\hline C4 & 0.67 & 1.00 & 2.00 & 0.50 & 1.00 & 1.50 & 0.50 & 0.67 & 1.00 & 1.00 & 1.00 & 1.00 & 0.40 & 0.50 & 0.67 & 3.50 & 4.00 & 4.50 & 0.50 & 1.00 & 1.50 & 0.50 & 1.00 & 1.50 \\
\hline C5 & 0.50 & 1.00 & 1.50 & 1.50 & 2.00 & 2.50 & 0.67 & 1.00 & 2.00 & .50 & .00 & 2.50 & 1.00 & 1.00 & 1.00 & 4.00 & 4.50 & 4.50 & 2.00 & 2.50 & 3.00 & 5.00 & 2.50 & 3.00 \\
\hline C6 & 0.22 & 0.22 & 0.25 & 3.00 & 3.50 & 4.00 & 0.22 & 0.22 & 0.25 & 0.22 & 0.25 & 0.29 & 0.22 & 0.22 & 0.25 & 1.00 & 1.00 & 1.00 & 0.25 & 0.29 & 0.33 & 0.25 & 0.29 & 0.33 \\
\hline C7 & 0.50 & 0.67 & 1.00 & 0.67 & 1.00 & 2.00 & 0.33 & 0.40 & 0.50 & 0.67 & 1.00 & 2.00 & 0.33 & 0.40 & 0.50 & 0.67 & 1.00 & 2.00 & 1.00 & 1.00 & 1.00 & 0.50 & 1.00 & 1.50 \\
\hline C8 & 0.50 & 0.67 & 1.00 & 0.67 & 1.00 & 2.00 & 0.33 & 0.40 & 0.50 & 0.67 & 1.00 & 2.00 & 0.33 & 0.40 & 0.50 & 3.00 & 3.50 & 4.00 & 3.00 & 3.50 & 4.00 & 1.00 & 1.00 & 1.00 \\
\hline
\end{tabular}

\subsubsection{Determining the Fuzzy Synthesis value limit (Si)}

To obtain the Synthesis value limit ( $\mathrm{Si}$ ) two steps are taken, the first is to calculate the lower (1), median (m) and upper (u) values for each criterion. Fuzzy (Si) Formula:

$S_{i}=\sum_{j=1}^{m} M_{g i}^{j} X\left[\sum_{i=1}^{n} \sum_{j=1}^{m} M_{g i}^{i}\right]^{-1}$

where:

$\sum_{j=1}^{m} M_{g i}^{j}=\sum_{j=1}^{m} l_{j}, \sum_{j=1}^{m} m_{j}, \sum_{j=1}^{m} u_{j}$

$\left[\sum_{i=1}^{n} \sum_{j=1}^{m} M_{g i}^{j}\right]^{-1}=\frac{i}{\sum_{j=1}^{n} u_{j} \sum_{j=1}^{n} m_{j} \sum_{j=1}^{n} l_{j}}$

Definition:

$S i=$ Synthesis Fuzzy Value
$\mathrm{M}=\mathrm{TFN}$

$\mathrm{i}=$ Row index

$\mathrm{j}=$ Column index

$\sum_{j=1}^{n} M_{g i}^{j}=$ The total value of each column starting from column 1 in each

$\sum_{j=1}^{n} l_{j}=$ total value of 1 in each first column (lower)

$\sum_{j=1}^{n} m_{j} \quad=$ total value of $\mathrm{m}$ in each first

column (medium)

$\sum_{j=1}^{n} u_{j}=$ total value of $\mathrm{u}$ in each first column (upper)

Formulas 1, 2 and 3 define the formula for calculating $\mathrm{Si}$ where this calculation refers to the data $1, \mathrm{~m}$ and $\mathrm{u}$ in Table 9. From the calculation results, the total of each criterion is presented in Table 10. 
Table 10. Total lower, median and upper for each criteria

\begin{tabular}{lrrr}
\hline Criteria & $\sum_{j=\mathbf{1}}^{\boldsymbol{n}} \boldsymbol{l}_{\boldsymbol{j}}$ & $\sum_{\boldsymbol{j}=\mathbf{1}}^{\boldsymbol{n}} \boldsymbol{m}_{\boldsymbol{j}}$ & $\sum_{\boldsymbol{j}=\mathbf{1}}^{\boldsymbol{n}} \boldsymbol{u}_{\boldsymbol{j}}$ \\
\hline C1 & 9.67 & 12.67 & 16.00 \\
C2 & 4.15 & 5.85 & 8.50 \\
C3 & 16.50 & 17.00 & 20.00 \\
C4 & 7.57 & 10.17 & 13.67 \\
C5 & 16.17 & 16.50 & 20.00 \\
C6 & 5.39 & 5.99 & 6.70 \\
C7 & 4.67 & 6.47 & 10.50 \\
C8 & 9.50 & 11.47 & 15.00 \\
\hline Total & 73.61 & 86.11 & 110.37 \\
\hline
\end{tabular}

The second step is to calculate the synthesis value of the total $1, \mathrm{~m}$ and $\mathrm{u}$ that have been obtained previously (Table 13.). Calculations are performed using Formulas 4, 5 and 6.

Calculate the Fuzzy synthesis value at lower using Formula 4:

$S_{i}=\sum_{j=1}^{n} l j \mathrm{X} \frac{1}{\sum_{i=1}^{n} \sum_{j=1}^{m} u_{j}}$

Calculate the value of Fuzzy synthesis on the median using the formula 5 :

$S_{i}=\sum_{j=1}^{n} m_{j} \mathrm{X} \frac{1}{\sum_{i=1}^{n} \sum_{j=1}^{m} m_{j}}$

Calculate the value of Fuzzy synthesis on upper using formula 6 :

$S_{i}=\sum_{j=1}^{n} u_{j} \mathrm{X} \frac{1}{\sum_{i=1}^{n} \sum_{j=1}^{m} l_{j}}$
From the calculation of the synthetic limit value (Si), the results are presented in Table 11.

Table 11. Synthesis Value limit

\begin{tabular}{cccc}
\hline Criteria & $\mathbf{l}$ & $\begin{array}{c}\boldsymbol{S}_{\boldsymbol{i}} \\
\mathbf{~ m}\end{array}$ & $\mathbf{u}$ \\
\hline C1 & 0.088 & 0.15 & 0.22 \\
C2 & 0.038 & 0.07 & 0.12 \\
C3 & 0.149 & 0.20 & 0.27 \\
C4 & 0.069 & 0.12 & 0.19 \\
C5 & 0.146 & 0.19 & 0.27 \\
C6 & 0.049 & 0.07 & 0.09 \\
C7 & 0.042 & 0.08 & 0.14 \\
C8 & 0.086 & 0.13 & 0.20 \\
\hline
\end{tabular}

\subsubsection{Determining the Fuzzy AHP Priority Vector (V) value}

This stage is to determine the value of the Fuzzy AHP priority vector (V) based on the FAHP calculation steps according to Chang using Formula 7:

$V\left(M_{2} \geq M_{1}=\left\{\begin{array}{c}1, \text { if } m_{2} \geq m_{1} \\ 0, \text { if } l_{1} \geq m_{2} \\ \frac{l_{1}-u_{2}}{\left(m_{2}-u_{2}\right)-\left(m_{1}-l_{1}\right)}, \text { other }\end{array}\right.\right.$

Where:

$M_{i} \quad=$ Triangular Fuzzy Number from each criteria $\mathrm{Ci}$.

The results of calculating the priority of the fuzzy AHP vector are presented in Table 12.

Table 12. Fuzzy AHP priority vector value

\begin{tabular}{ccccccccc}
\hline & C1 & C2 & C3 & C4 & C5 & C6 & C7 & C8 \\
\hline C1 & 1.000 & 1.000 & 0.574 & 1.000 & 0.614 & 1.000 & 1.000 & 1.000 \\
C2 & 0.261 & 1.000 & -0.356 & 0.484 & -0.335 & 0.977 & 0.911 & 0.311 \\
C3 & 1.000 & 1.000 & 1.000 & 1.000 & 1.000 & 1.000 & 1.000 & 1.000 \\
C4 & 0.772 & 1.000 & 0.313 & 1.000 & -0.053 & 1.000 & 1.000 & 0.868 \\
C5 & 1.000 & 1.000 & 0.955 & 1.000 & 1.000 & 1.000 & 1.000 & 1.000 \\
C6 & 0.043 & 1.000 & -0.842 & 0.317 & -0.831 & 1.000 & 0.898 & 0.064 \\
C7 & 0.035 & 1.000 & -0.059 & 0.633 & -0.034 & 1.000 & 1.000 & 0.494 \\
C8 & 0.893 & 1.000 & 0.458 & 1.000 & 0.495 & 1.000 & 1.000 & 1.000 \\
\hline
\end{tabular}

\subsubsection{Determining ordinate of Defuzzification (d')}

Based on the calculation steps FAHP in Formula 9. In determining the value of the defuzzification ordinate is to find the minimum value of the vector value of each criterion.

$d^{\prime}\left(A_{i}=\min V\left(S_{i} \geq S_{k}\right)\right.$

to $\mathrm{k}=1,2, \ldots, \mathrm{n} ; \mathrm{k} \neq i$, then the application of the defuzzification ordinate

$d^{\prime}\left(C_{1}=\min (C 1, C 2, C 3, C 4, C 5, C 4, C 7, C 8)\right)$ and generate data as in Table 13.
Table 13. Defuzzification ordinate (d')

\begin{tabular}{cc}
\hline Criteria & Defuzzification \\
\hline C1 & 0.574 \\
C2 & -0.356 \\
C3 & 1.000 \\
C4 & -0.053 \\
C5 & 0.955 \\
C6 & -0.842 \\
C7 & -0.059 \\
C8 & 0.458 \\
\hline
\end{tabular}




\subsubsection{Normalization of vector weight values}

Based on the FAHP calculation steps in Formula 10 , the normalization of the fuzzy vector weight value $(\mathrm{W})$ is as follows:

$\left.W^{\prime}=\left(d^{\prime}\left(A_{1}\right), d^{\prime}\left(A_{1}\right) \ldots, d\left(A_{n}\right)\right)\right)^{T}$

Where $A_{1}=1,2, \ldots, \mathrm{n}$ adalah $\mathrm{n}$ decision element. After normalization of the $W^{\prime}$ formula, the normalized vector weight value is like equation 11:

$\left.W=\left(d^{\prime}\left(A_{1}\right), d^{\prime}\left(A_{1}\right) \ldots, d\left(A_{n}\right)\right)\right)^{T}$

Where $\mathrm{W}$ is a non-fuzzy number and the value of $\sum W=1$.

$W^{\prime}=$

$(0.574,-0.356,1.000,-0.053,0.955,-0.842,-0.059,0.458)$

$\sum W=(0.574+(-0.356)+1.000+(-0.053)+$

$(0.955)+(-0.842)+(-0.059)+0.458)=1.677$

$\mathrm{W}=$

$(0.574+(-0.356)+1.000+(-0.053)+(0.955)+(-0.842)+(-0.059)+$

$$
0.458
$$

, where the calculation results are presented in Table 14.

Table 14. Normalization of vector weight value

\begin{tabular}{cc}
\hline$C_{i}$ & $\mathrm{~W}$ \\
\hline $\mathrm{C} 1$ & 0.342 \\
$\mathrm{C} 2$ & -0.213 \\
$\mathrm{C} 3$ & 0.596 \\
$\mathrm{C} 4$ & -0.031 \\
$\mathrm{C} 5$ & 0.569 \\
$\mathrm{C} 6$ & -0.502 \\
\hline
\end{tabular}

Table 15. Maximum and minimum value

\begin{tabular}{lcccccccc}
\hline \multicolumn{1}{c}{ Alternative } & \multicolumn{7}{c}{ Criteria } \\
& C1 & C2 & C3 & C4 & C5 & C6 & C7 & C8 \\
\hline A1 - Relationship Building & 126 & 128 & 129 & 123 & 120 & 100 & 120 & 123 \\
A2 - Reciprocal Sustainment & 122 & 113 & 122 & 114 & 122 & 102 & 118 & 118 \\
A3 - Reciprocal Assistant & 120 & 110 & 121 & 111 & 125 & 106 & 116 & 114 \\
A4 - Active Support & 119 & 115 & 123 & 122 & 124 & 109 & 109 & 107 \\
$\quad$ Max & 126 & 128 & 129 & 123 & 125 & 109 & 120 & 123 \\
Min & 119 & 110 & 121 & 111 & 120 & 100 & 109 & 107 \\
\hline
\end{tabular}

\subsubsection{Determining of vector weight in criteria (W)}

Determining the value of the vector weight on the criteria (W) based on Formula 14, the following is the calculation process for $\mathrm{C} 1$ :

$\mathrm{A} 1=\frac{126-119}{126-119}=1$

\begin{tabular}{lc}
\hline $\mathrm{C} 7$ & -0.035 \\
$\mathrm{C} 8$ & 0.273 \\
\hline
\end{tabular}

\subsubsection{Determining of vector weight value}

Determine the vector weight value using equation 12.

$b_{i j}=\frac{a_{i j}-a_{j}^{\min }}{a_{j}^{\text {max }}-a_{j}^{\text {min }}}$

Where,

$a_{j}^{\max }=\max \left(a_{1 j}, a_{1 j}, a_{1 j}, \ldots, a_{m j}\right.$

$a_{j}^{\min }=\min \left(a_{1 j}, a_{1 j}, a_{1 j}, \ldots, a_{m j}\right.$

$i=1,2, \ldots, \mathrm{m}, j=1,2, \ldots, \mathrm{n}$

8fter that, normalize the weight vector for each criterion that represents the weight of each alternative with the total weight value $=1$. Then the ranking process and decision results are carried out by calculating the total score with formula 13

$S_{j}=\sum\left(S_{i j}\right)\left(W_{i}\right)$

Where:

$S_{j}=$ Score

$S_{i j}=$ the weight of each criterion which represents the weight of $S_{j}$

$W_{i}=$ Weight of every criteria

The results of these calculations select the highest score where the highest score is the most recommended. Finding the maximum and minimum values for each criterion is presented in Table 15.

$$
\begin{aligned}
& \mathrm{A} 2=\frac{122-119}{126-119}=0.4286 \\
& \mathrm{~A} 3=\frac{120-119}{126-119}=0.142 \\
& \mathrm{~A} 4=\frac{119-119}{126-119}=0
\end{aligned}
$$

For C2, C3, C4, C5, C6, C7 and C8 using the same formulas, the overall results of the weight vector values in Table. 16 are obtained. 
Table 16. Vector weight value (W) specification criteria

\begin{tabular}{lcccccccc}
\hline \multicolumn{1}{c}{ Alternative } & \multicolumn{1}{c}{ Criteria } & \multicolumn{1}{c}{ C6 } & \multicolumn{1}{c}{ C8 } \\
\hline A1 - Relationship Building & C1 & C2 & C3 & C4 & C5 & C6 & C \\
A2 - Reciprocal Sustainment & 0.429 & 0.167 & 0.125 & 0.25 & 0.4 & 0.222 & 0.818 & 0.69 \\
A3 - Reciprocal Assistant & 0.143 & 0 & 0 & 0 & 1 & 0.667 & 0.636 & 0.44 \\
A4 - Active Support & 0 & 0.278 & 0.25 & 0.917 & 0.8 & 1 & 0 & 0 \\
\hline
\end{tabular}

In calculating the score by multiplying the value of the weight vector (w) (Table 14.) with the value of the weight vector $(\mathrm{w})$ for each criterion (Table 16.) which represents the weight of each as in Formula 13. The following is the calculation of the total score in alternative 1 (A1):

$$
\begin{aligned}
\mathrm{A} 1= & (1 \mathrm{X} 0.342)+(1 \mathrm{X}-0.213)+(1 \mathrm{X} 0.596)+(1 \mathrm{X}- \\
& 0.031)+(0 \mathrm{X} 0.596)+(0 \mathrm{X}-0.502)+(1 \mathrm{X}-0.035) \\
& +(1 \mathrm{X} 0.273)=\mathbf{0 . 9 3 3}
\end{aligned}
$$

$\mathrm{A} 2=(0.429 \mathrm{X} 0.342)+(0.167 \mathrm{X}-0.213)+(0.125 \mathrm{X}$ $0.596)+(0.25 X-0.031)+(0.4 X 0.596)+(0.222$ $X-0.502)+(0.818 X-0.035)+(0.69 \times 0.273)=$ $\mathbf{0 . 4 5 3}$

$\mathrm{A} 3=(0.143 \mathrm{X} 0.342)+(0 \mathrm{X}-0.213)+(0 \mathrm{X} 0.596)+(0 \mathrm{X}$ $-0.031)+(1 X 0.596)+(0.667 X-0.502)+(0.636$ $\mathrm{X}-0.035)+(0.44 \times 0.273)=\mathbf{0 . 3 8 1}$

$\mathrm{A} 4=(0 \mathrm{X} 0.342)+(0.278 \mathrm{X}-0.213)+(0.25 \mathrm{X} 0.596)+$ $(0.917 \times-0.031)+(0.8 \times 0.596)+(1 X-0.502)+$ $(0 \mathrm{X}-0.035)+(0 \times 0.273)=\mathbf{0 . 0 1 5}$

Table 17. Vector weight value (w) specification criteria

\begin{tabular}{lccccccccc}
\hline \multicolumn{1}{c}{ Alternative } & \multicolumn{1}{c}{ Criteria } & \multicolumn{4}{c}{ Weight } \\
& $\mathrm{C} 1$ & $\mathrm{C} 2$ & $\mathrm{C} 3$ & $\mathrm{C} 4$ & $\mathrm{C} 5$ & $\mathrm{C} 6$ & $\mathrm{C} 7$ & $\mathrm{C} 8$ & Score \\
\hline A1 - Relationship Building & 1 & 1 & 1 & 1 & 0 & 0 & 1 & 1 & 0.933 \\
A2 - Reciprocal Sustainment & 0.4 & 0.17 & 0.1 & 0.3 & 0.4 & 0.2 & 0.8 & 0.7 & 0.453 \\
A3 - Reciprocal Assistant & 0.1 & 0 & 0 & 0 & 1 & 0.7 & 0.6 & 0.4 & 0.381 \\
A4 - Active Support & 0 & 0.3 & 0.3 & 0.9 & 0.8 & 1 & 0 & 0 & 0.015 \\
\hline
\end{tabular}

From the results of the Fuzzy AHP weighting, the ranking parameters (Table 18.) and (Figure 4.) are generated. The highest rank is Relationship Building (RB) with a score of $0.933(52.86 \%)$, the second rank is Reciprocal Sustainment (RS) with a score of 0.453 (25.44\%), the third rank is Reciprocal Assistant (RA) with a score of $0.381(21.77 \%)$ and the last rank is is Active Support (US) with a score of 0.015 (0.83\%).

Table 18. Ranking of parameter based on Fuzzy AHP with Octalysis Core Drive criteria

\begin{tabular}{lcc}
\hline \multicolumn{1}{c}{ Alternative } & Weight Score & Ranking \\
\hline A1 - Relationship & 0.933 & Rank 1 \\
$\begin{array}{l}\text { Building } \\
\text { A2 - Reciprocal }\end{array}$ & 0.453 & Rank 2 \\
$\begin{array}{l}\text { Sustainment } \\
\text { A3 - Reciprocal }\end{array}$ & 0.381 & Rank 3 \\
Assistant & 0.015 & Rank 4 \\
A4 - Active Support & & \\
\hline
\end{tabular}

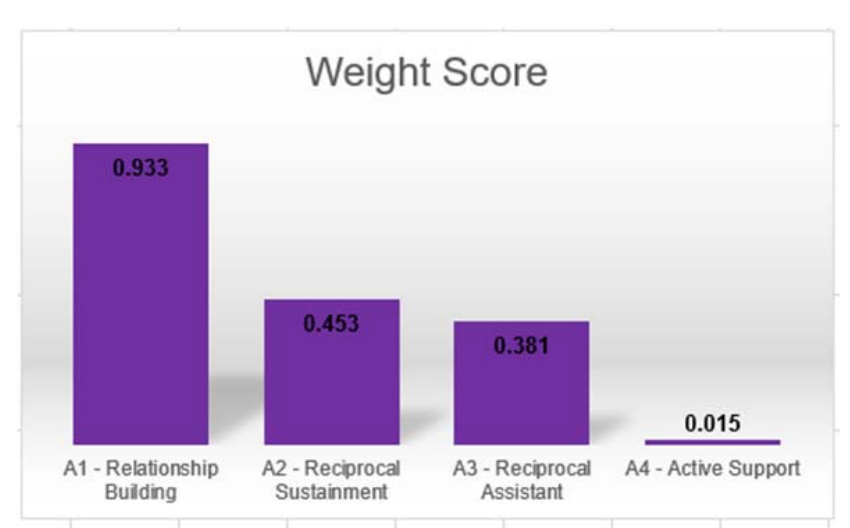

Figure 4. Graph of parameter ranking

\section{Conclusion and Future Works}

Weak motivation for SME collaboration. Based on testing and data analysis from this study, it can be concluded that the 4 Principles of "Silaturrahmi" culture can be assimilated into collaboration parameters through linear regression statistical tests. The resulting parameters are Relationship Building (RB), Reciprocal Sustainment (RS), Reciprocal Assistant (RA) and Active Support (AS). Parameters can be used to measure collaboration performance and also become a reference for detailed design of collaboration activities. Therefore, the parameters need to be tested for the level of potential motivation with an octalysis gamification approach that details motivation with 8 core drives.

The parameters were tested to produce the weight of each core drive using Fuzzy AHP by involving the core drive as the criteria. The calculation of the Octalysis scale shows results that are in line with the results of the Fuzzy AHP test, especially in determining the first rank of the parameter. Based on the results of the Fuzzy AHP test, it is shown that "Relationship Building (RB)" is ranked first with a weight of $52.86 \%$, while "Active Support (AS)" is in the last rank with a weight of $0.83 \%$. These two parameters produce values with extreme differences, so it is necessary to conduct a more detailed study in future research to determine the cause, and in the short term it can be taken into consideration for designing the priority of collaboration activities to be more targeted. 
Subsequent research in addition to studying further about the causes of the extreme difference in motivational weights is necessary to design the implementation of a collaboration model that applies parameters as a performance reference to improve the collaboration framework.

\section{Acknowledgements}

The appreciation goes their gratitude to all who participated to this research: DRPM KEMENRISTEK BRIN, Universiti Teknikal Malaysia Melaka (UTeM); Malaysia, Widyagama University of Malang, Indonesia; President University, Indonesia; Indonesia, and all colleagues who provided added value for this article are greatly appreciated by authors.

\section{References}

[1]. Bhoganadam, S., Rao, N., \& Dasaraju, S. (2017). A study on Issues and Challenges faced by SMEs: A Literature Review. Research Journal of SRNMC, 1, 48-56.

[2]. Yoshino, N., \& Taghizadeh Hesary, F. (2016). Major challenges facing small and medium-sized enterprises in Asia and solutions for mitigating them. Tokyo: Asian Development Bank Institute.

[3]. Llave, M. R. (2017). Business intelligence and analytics in small and medium-sized enterprises: A systematic literature review. Procedia Computer Science, 121, 194-205.

[4]. Patricio, J., Axelsson, L., Blomé, S., \& Rosado, L. (2018). Enabling industrial symbiosis collaborations between SMEs from a regional perspective. Journal of cleaner production, 202, 1120-1130.

[5]. Tiwari, V. (2020). Impact of Coronavirus (Covid-19) on Indian Economyand Supply Chain. : 2020, 166.

[6]. Benson, V., \& Filippaios, F. (2019). The role of learning analytics in networking for business and leisure: A study of culture and gender differences in social platform users. Computers in Human Behavior, 92, 613-624.

[7]. Johannsdottir, L., \& McInerney, C. (2018). Developing and using a Five $\mathrm{C}$ framework for implementing environmental sustainability strategies: A case study of Nordic insurers. Journal of Cleaner Production, 183, 1252-1264.

[8]. Leckel, A., Veilleux, S., \& Dana, L. P. (2020). Local Open Innovation: A means for public policy to increase collaboration for innovation in SMEs. Technological Forecasting and Social Change, 153, 119891.

[9]. Shirazi, B. (2018). Towards a sustainable interoperability in food industry small \& medium networked enterprises: Distributed service-oriented enterprise resources planning. Journal of cleaner production, 181, 109-122.

[10]. Ko, W. W. J., Liu, G., Ngugi, I. K., \& Chapleo, C. (2018). External supply chain flexibility and product innovation performance: A study of small-and medium-sized UK-based manufacturers. European Journal of Marketing.
[11]. Ajdari, P., \& Talebi, K. (2015). The Effect of Networking Behavior on the Reduction of Innovation Obstacles to Small and Medium-Sized Enterprises. International Journal of Academic Research in Business and Social Sciences, 5(3), 419.

[12]. Gausdal, A. H. (2015). Methods for developing innovative SME networks. Journal of the knowledge economy, 6(4), 978-1000.

[13]. Wasida, L. Y., Kaunang, R. A., \& Manoppo, F. K. (2019, August). Silaturahmi (Gathering) Tradition of Muslim-Christian Families in Kampung Jawa Tondano. In 1st Annual Internatioal Conference on Social Sciences and Humanities (AICOSH 2019) (pp. 254-257). Atlantis Press.

[14]. Warisno, A. (2017). Tradisi Tahlilan Upaya Menyambung Silaturahmi. Riayah: Jurnal Sosial dan Keagamaan, 2(02), 69-97.

[15]. Darussalam, A. (2017). Wawasan Hadis tentang Silaturahmi. Tahdis: Jurnal Kajian Ilmu AlHadis, 8(2).

[16]. Landsell, J., \& Hägglund, E. (2016). Towards a Gamification Framework: Limitations and opportunities when gamifying business processes. Faculty of social sciences, Department of informatics, Umeå University.

[17]. Chou, Y. K. (2019). Actionable gamification: Beyond points, badges, and leaderboards. Packt Publishing Ltd.

[18]. Marisa, F., Ahmad, S. S. S., Yusoh, Z. I. M., Maukar, A. L., Marcus, R. D., \& Widodo, A. A. (2020). Evaluation of Student Core Drives on eLearning during the Covid-19 with Octalysis Gamification Framework. Evaluation, 11(11).

[19]. Marisa, F., Sakinah, S., Ahmad, S., \& Mohd, Z. I. (2020). Analysis Of Relationship CLV with 8 Core Drives Using Clustering K-Means and Octalysis Gamification Framework. J. Theor. Appl. Inf. Technol, 98(20), 3151-3164.

[20]. Freitas, S. A. A., Lacerda, A. R., Calado, P. M., Lima, T. S., \& Canedo, E. D. (2017, October). Gamification in education: A methodology to identify student's profile. In 2017 IEEE Frontiers in Education Conference (FIE) (pp. 1-8). IEEE.

[21]. Liu, Y., Eckert, C. M., \& Earl, C. (2020). A review of fuzzy AHP methods for decision-making with subjective judgements. Expert Systems with Applications, 113738.

[22]. Wang, Y., Xu, L., \& Solangi, Y. A. (2020). Strategic renewable energy resources selection for Pakistan: Based on SWOT-Fuzzy AHP approach. Sustainable Cities and Society, 52, 101861.

[23]. Emrouznejad, A., \& Ho, W. (2017). Fuzzy analytic hierarchy process. CRC Press.

[24]. Fan, Y., Li, Z., \& Yang, H. (2020, June). Study on Scheme Optimization of Urban Water Diversion Project based on Fuzzy AHP-TOPSIS. In 2020 5th International Conference on Smart Grid and Electrical Automation (ICSGEA) (pp. 627-630). IEEE. 
[25]. Son, A. Y., Lim, Y. S., \& Huh, E. N. (2018, October). Energy Efficient VM Placement Scheme Based on Fuzzy-AHP System for Sustainable Cloud Computing. In 2018 Second World Conference on Smart Trends in Systems, Security and Sustainability (WorldS4) (pp. 260-265). IEEE.

[26]. Fernández-Olmos, M., \& Ramírez-Alesón, M. (2017). How internal and external factors influence the dynamics of SME technology collaboration networks over time. Technovation, 64, 16-27.

[27]. Adornes, G. S., \& Muniz, R. J. (2019). Collaborative technology and motivations: utilization, value and gamification. INMR-Innovation \& Management Review, 16(3), 280-294.

[28]. Morschheuser, B., Maedche, A., \& Walter, D. (2017, February). Designing cooperative gamification: Conceptualization and prototypical implementation. In Proceedings of the 2017 ACM Conference on Computer Supported Cooperative Work and Social Computing (pp. 2410-2421).
[29]. Hanik, U., \& Zahid, A. Z. A. (2020). Disparity of Silaturrahmi Culture and New Way of Society on Globalization Era. Asketik: Jurnal Agama dan Perubahan Sosial, 4(2), 255-270.

[30]. Seise, P. C. (2020). Localized Islamic Concepts i35n Diplomacy: The Example Of Silaturahmi. Prodising ISID, (1), 21-27.

[31]. Rianti, A., Novenia, A. E., Christopher, A., Lestari, D., \& Parassih, E. K. (2018). Ketupat as traditional food of Indonesian culture. Journal of Ethnic Foods, 5(1), 4-9.

[32]. Hendarsjah, H., Susanto, E., Lies Sugianto, B. R., \& Handoko, T. H. (2019). Curvilinear relationship between intra-team trust and team innovation: the moderating role of task complexity. Journal of Asia Business Studies, 13(3), 472-487.

[33]. Usman, H., Sobari, N., \& Sari, L. E. (2019). Sharia motivation in Muslim tourism definition, is it matter?. Journal of Islamic Marketing, 10(3), 709723.

[34]. Chou, Y. K. (2019). Actionable gamification: Beyond points, badges, and leaderboards. Packt Publishing Ltd. 